\title{
The Aura of Materiality:
}

\section{Digital Surrogacy and the Preservation of Photographic Archives}

Jasmine E. Burns, Cornell University

\begin{abstract}
Through a discussion of the materiality of photographic documents and the inherent qualities of digital objects, this article examines the viability of digitization as a method of archival photographic preservation. By exploring notions of surrogacy, originality, and aura, the author presents and deconstructs the popular argument that digital versions of material photographs preserve a representation of the object's content rather than a reproduction of its material form. The process of digitization therefore brings forth a wholly new object into existence. The author's argument against this common perception is that, rather than eliminating the material evidence of the object's existence, the digitization of these materials and the subsequent dissemination of photographic surrogates enhances those material qualities that are not inherently represented in the digital object.
\end{abstract}

\section{NTRODUCTIO N}

The Society of American Archivists' online glossary of archival terminology defines preservation as "the professional discipline of protecting materials by minimizing chemical and physical deterioration and damage to minimize the loss of information and to extend the life of cultural property" and "the act of keeping from harm, injury, decay, or destruction, especially through noninvasive treatment." The broad scope and vague language of these definitions invite a variety of interpretations regarding the nature and practice of archival preservation.

Archivists and librarians undertake numerous preservation initiatives that protect the material integrity of their collections, and they are now discovering how to extend

\footnotetext{
Jasmine E. Burns is visual resources metadata librarian at Cornell University, Ithaca, New York; jburns@cornell.edu.

I. Society of American Archivists, "Glossary of Archival Records and Terminology: Preservation," http://www2 .archivists.org/glossary/terms/p/preservation.
}

Art Documentation: Journal of the Art Libraries Society of North America, vol. 36 (spring 2017)

0730-7187/2017/3601-0001 \$10.00. (C) 2017 by The Art Libraries Society of North America. All rights reserved. 
the life of their born-digital information and digitized objects through digital preservation. In most institutions, material and digital preservation processes and procedures are considered separate areas that require different sets of skills and approaches. ${ }^{2}$ This division of formats applies not only to the practices of preservation, but also to collection management in general. A potential consequence of this intellectual division is that digital surrogates of material objects (i.e., a JPEG file that is a digital scan of a $35 \mathrm{~mm}$ slide) become far removed from their physical counterparts. Archivists have generally rejected the notion that surrogates carry any archival value as a result of this, ${ }^{3}$ and their value is therefore measured primarily through the provision of immediate access to the visual and/or textual content of the original object.

Photographic materials in particular are considered excellent candidates for digitization efforts because their material forms (i.e., negatives, filmstrips, slides, and a variety of print styles) lend themselves well to digital reformatting. Archival photographs are unique in that they are most often considered to be documentary by nature, so to provide additional access to their visual content is considered a valuable use of resources. However, although there are many digital collections and projects that incorporate archival photographs, the digital materials are linked to a larger preservation initiative only through the notion that the originals are subject to less wear and tear.

This article examines the viability of digitization as a method of preserving photographic materials through what the author has termed "virtuality." It is often argued that digital versions of material photographs preserve a representation of the object's content rather than a reproduction of its material form. This distinction highlights the elimination of the evidence of the object's manufacture and the patterns of its use, which are arguably those qualities that define the object as a document from an archival perspective. Without such evidence, rather than preserving photographic materials in their original form, the process of digitization creates an entirely new material object: a digital surrogate that represents the original virtually. These surrogates are not meant to act as a replacement for the original; however, their documentary value through electronic expression should not be dismissed. The author examines issues of surrogacy and originality to further explain the concept of virtuality as a representational medium for constructing an alternate custodial narrative for the photographic object.

\section{LITERAT URE REVIEW}

Due to the rather insular and practical nature of archival literature, it is necessary to incorporate a body of texts external to those of archives in this investigation. The three major themes that shape this article are digital surrogacy, materiality, and archival

2. The SAA Glossary does not define digital preservation as a separate term; however, the language in the definition of "preservation" notes specifically the "chemical and physical deterioration and damage," which does not necessarily apply to digital objects and files.

3. Paul Conway, "Digital Transformations and the Archival Nature of Surrogates," Archival Science I5, no. I (March 20I5): 6 . 
photographs. The interdisciplinary lens through which these elements are explored derives from the fields of anthropology, art history, and sociology, among others.

There has been much debate in the archival community regarding the nature and place of digital surrogates in the archives and their status as vessels of preservation. Digital surrogates are defined by Murtha Baca at the Getty Research Institute as "a digital "copy' of an original work or item," ${ }^{4}$ and the process of digitizing these materials is considered to separate the form from the content of that original work. In Paul Conway's article "Digital Transformations and the Archival Nature of Surrogates," he addresses the potential archival value of such surrogates. Although archival materials (photographs in particular) are widely subjected to digitization efforts, Conway states that archivists have generally rejected the notion that surrogates carry any archival value because they are too far removed from the original document or object. ${ }^{5}$ Value, in an archival sense, is defined as the "ongoing usefulness or significance of records, based on the administrative, legal, fiscal, evidential, or historical information that they contain" 6 and is determined through a process called appraisal. Conway, however, argues that the digital surrogates of archival materials are independent of their sources and should therefore be treated as being equal to all archival records during the assignment of value. ${ }^{7}$

In any discussion of digitization and digital reformatting, one must also address the material qualities of archival collections. Although materiality studies are based largely in the field of anthropology, ${ }^{8}$ such theories are more recently being applied to archival literature through a deeply postmodern lens. Ala Rekrut, in her article "Material Literacy: Reading Records as Material Culture," highlights the manner in which material forms communicate meaning and contextual evidence. She states that these forms should be valued as a data source and should therefore be incorporated into the aforementioned process of archival appraisal. Rekrut discusses the ways in which "improved material literacy can be a means to enrich the preservation of meaning in records and in archives."9 The juxtaposition of Rekrut's and Conway's arguments demonstrates the competing nature of materiality and virtuality when determining the archival value of each type of material.

In applying notions of material culture studies to photographic archives, authors such as Elizabeth Edwards, Joanna Sassoon, and Joan Schwartz argue that the physical form of the photograph should be a larger focus of archival appraisal. They claim that the photograph is more than just an object to be mined for its superficial content, and that an examination of this three-dimensionality reveals the context of its creation and existence. A recurring theme in these texts used to support the discussion of ma-

4. Murtha Baca, "Glossary," in Introduction to Metadata, ed. Murtha Baca (Los Angeles: Getty Publications, 20I6), http://www.getty.edu/publications/intrometadata/glossary/.

5. Conway, "Digital Transformations and the Archival Nature of Surrogates," 6.

6. Society of American Archivists, "Glossary of Archival Records and Terminology: Archival Value," http://www2 .archivists.org/glossary/terms/a/archival-value.

7. Conway, "Digital Transformations and the Archival Nature of Surrogates," 2.

8. An exemplary text is Daniel Miller's Materiality (Durham, NC: Duke University Press, 2005).

9. Ala Rekrut, “Material Literacy: Reading Records as Material Culture," Archivaria, no. 60 (Fall 2005 ): I2. 
teriality is Walter Benjamin's concept of "aura," which he describes in his essay "The Work of Art in the Age of Mechanical Reproduction." Benjamin defines aura as that which is tied to the situation of the original through ritual and a physical state of being. ${ }^{\text {IO }}$ His argument that aura is lost when a work of art is reproduced mechanically is frequently cited in discussions of digital cultural heritage and is used to support the notion that digital surrogates eliminate the materiality of the original object.

These arguments for the superior value of physical attributes are the foundation for the general consensus that digital reformatting does not equate to preservation. This tension between digital files and their physical sources is a major focus in the field and acts as an unnecessary barrier that essentially distracts archivists, librarians, and researchers from discovering the potential new users, innovative uses, and any creative re-envisioning of what an archive is/does/provides.

\section{MATERIALITY: PHOTOGRAPHS AND ARCHIVES}

Photographs, as three-dimensional objects, often serve a variety of functions in archival collections. They are sometimes physically separated from their collection of origin and are often organized by subject matter for purposes of access. However, a discussion of their value cannot exclude mention of the material qualities related to their manufacture and/or existence before their addition into an institutional collection, i.e., daguerreotype, glass plate, print, mounted, cropped, annotated, framed, etc.

Joan Schwartz argues it is the significance of the material form of photographic materials, rather than the content alone, that is essential to the object being understood as an archival document. Through this lens, the material form creates a singular object, and even with multiplicity of content the unique object prevails. This can be further explained through the concept of the photographic "original," which functions differently for such materials. In this case, the negative is generally considered to be the "truest record," but it is not intended to become the final product that will eventually convey a message to an audience. Thus, the negative is considered a draft. ${ }^{\text {II }}$ It is this notion of the negative as a draft that so strongly highlights the "transformation of the photographic image into a photographic document." ${ }^{12}$

The construction of multiple technical and presentational forms, even of the same image, has the potential to reveal the intention of the creator, as each object embodies its own unique existence and purpose. ${ }^{13}$ Technical forms refer to the type of print created from the original negative, and presentational forms are the various methods and materials related to the way in which those prints are displayed and/or stored. Schwartz argues that the technical and physical choices in making photographs are not likely to be random. She states that "the choice of ambrotype over paper print implies a desire for uniqueness, the use of platinum over silver gelatin intimates an aware-

Io. Walter Benjamin, “The Work of Art in the Age of Mechanical Reproduction,” in Illuminations (New York: Stocken Books, I968), 2I7-5I.

II. Joan Schwartz, “'We Make Our Tools and Our Tools Make Us': Lessons from Photographs for the Practice, Politics, and Poetics of Diplomatics,” Archivaria, no. 40 (I995): 46.

I2. Ibid.

I3. Ibid. 
ness of status, the use of gold toning a desire for performance." ${ }^{\text {"I }}$ In addition to these stylistic choices, there are several potential presentational forms that also carry physical traces of past use, such as cabinet cards, album pages, mounts, and frames. ${ }^{15} \mathrm{~A}$ combination of these technical and presentational forms can reveal a great deal of information about how that singular object was used, displayed, and/or stored. Such information can be valuable to researchers in understanding the larger cultural context of the work itself or the artist's larger body of work.

When these images are scanned directly from a negative, they are translated purely for their content; they become distorted from their material form. However, the original "negative as a draft" maintains its value as a type of evidence of artistic practice and process, which is exemplified in the collecting practices of institutions such as the Prints and Photographs Division of the Library of Congress. The positive digital image is infinitely more useful to a range of users, as few people are actually able to read negatives. However, when separated from the negative and its collection of origin, whether in print or pixels, the image itself (i.e., the content) takes on new meanings and interpretations by existing in a number of contexts. Due to the variations in printing styles, materials, and options for cropping and mounting, "multiple photographic originals with similar or identical image content cannot be assumed to be duplicates." ${ }^{16}$

The custodial history exemplified in the presentational and material forms that are preserved in archival collections defines the documentary nature of photographs and serves to authenticate their content. The prevailing argument against digitization as preservation is that these forms are lost in the process of digital reformatting: the content is separated from the vessel, and the three-dimensionality is flattened on a screen. However, this argument does not give due credit to advancements in contemporary imaging technologies, nor to the interpretive labor of archivists and custodians of image collections.

\section{VIRTUALITY AS PRESERVATION}

Notwithstanding the unique material qualities of photographic collections, digital surrogates should be treated as individual objects, separate from their physical counterparts from which "the materiality argument can no longer be given pre-eminence." 7 The materiality of the original object is not "lost"; it is only translated into metadata and digital information. The physical photograph never ceases to be a three-dimensional object. However, the difference between reading a material image and viewing a digital collection online is merely phenomenological. This discrepancy in the interactive experience with such collections should not dictate the value of digital objects, but rather

\footnotetext{
I4. Ibid., 58.

I5. Elizabeth Edwards and Janice Hart, "Introduction: Photographs as Objects," in Photographs Objects Histories: On the Materiality of Images, ed. Elizabeth Edwards (London: Routledge, 2004), 3.

I6. Joanna Sassoon, “Photographic Meaning in the Age of Digital Reproduction,” Archives Q Social Studies: A Journal of Interdisciplinary Research I (March 2007): 303.

I7. Fiona Cameron, "Beyond the Cult of the Replicant: Museums and Historical Digital Objects-Traditional Concerns, New Discourses," in Theorizing Digital Cultural Heritage, ed. Fiona Cameron (Cambridge, MA: MIT Press, 2007$), 68$.
} 
be leveraged to expand an understanding of current archival practices and innovative uses for digitized collections.

The notion that a digital surrogate is somehow less valuable than the original derives from an object-centered culture with a focus on tactility, tangibility, and originality as authenticity. ${ }^{\mathrm{I}}$ Benjamin's argument that aura is lost through reproduction because it breaks with the original does not hold up for digital media. ${ }^{\text {I9 }}$ When this argument is used, it "represents a lack of understanding of [the surrogate's] materiality and thus denies the surrogate and indeed the digital historical object as a creative work in its own right, with a history and a provenance." 20

With the application of digital technologies, surrogates are imbued with a "secondary provenance" that is embedded into the custodial history of the original and is transferred into the digital form as a "trace" of its past use and material construction. ${ }^{2 \mathrm{I}}$ In creating digital surrogates, this evidence of manufacture and use communicated through the aforementioned material and presentational forms translates the technical processes of printing and developing film into a display of contemporary cultural practices regarding the creation and transfer of data. The information that relates how the file was constructed digitally is combined with the material evidence of the photograph's manufacture. ${ }^{22}$ This ties the two objects intellectually and situates the surrogate as an analogy of its archival source. In this way, the surrogate draws its significance from the ongoing narrative of its physical counterpart and serves as a mediator between the viewer of the surrogate and the creator of the original work.

Peter Walsh, in his discussion of the "Post-Photographic Museum," describes the reproduction as that which "confers status and importance in the original. The more reproduced an artwork is - and the more mechanical and impersonal the reproductions-the more important the original becomes." ${ }^{23}$ Anthropologist Dean MacCannell constructs a similar argument in his discussion of tourist site/sight markers, which he defines as any information about a sight/site. In the context of archival photographs, a marker would constitute the digital surrogate or any accompanying metadata about the object, and the site/sight would be the physical archival object. MacCannell reverses Benjamin's argument that aura is a residue of tradition and ritual and claims that "reproductions are the aura, and the ritual, far from being a point of origin, derives from the relationship between the original object and its socially constructed importance." ${ }^{24}$ As the object becomes fragmented and separated from its archival context, the surrogate points back to the original as a marker of its originality, authenticity, and materiality. To generalize this theory more widely, Bruno Latour states, “To stamp a piece

\footnotetext{
I8. Ibid.

I9. However, the argument is widely applied to modern technologies, particularly in the writings of Jean Baudrillard.

20. Cameron, "Beyond the Cult of the Replicant," 67.

2I. Conway, "Digital Transformations and the Archival Nature of Surrogates," 7.

22. Jasmine Burns, "Digital Facsimiles and the Modern Viewer: Medieval Manuscripts and Archival Practice in the Age of New Media," Art Documentation 33, no. 2 (Fall 20I4): 158.

23. Peter Walsh, "Rise and Fall of the Post-Photographic Museum: Technology and the Transformation of Art," in Theorizing Digital Cultural Heritage, ed. Fiona Cameron (Cambridge, MA: MIT Press, 2007), 29.

24. Dean MacCannell, The Tourist: A New Theory of the Leisure Class (Los Angeles: University of California Press, I999), 48, emphasis his.
} 
with the mark of originality requires the huge pressure that only a great number of reproductions can provide." 25

The creation of these markers through digital surrogacy and robust descriptive metadata preserves the content as well as the material context of photographic collections, so long as the process of selecting for digitization includes the capture of the entire object as a three-dimensional document for the final product. As a marker, the digital image itself is an additional form of metadata for the object, as it captures and preserves not only the content but also the current state of its material existence at a particular moment in time. The digital image solidifies the object in time. Because the original and its digital counterpart age differently, the surrogate essentially provides two versions of the same singular object. "The digital object does not age visually in a way that affects the object's surface, as the aging associated with the data manifests through processes of technological decay such as bit rot and media obsolescence." ${ }^{26}$ In this manner, the surrogate preserves previous stages of the physical object's existence, and with the addition of technical and descriptive metadata, the digital file is situated as a faithful and reliable reproduction of the original.

\section{CONCLUSIONS}

Just as the definition of preservation invites a variety of interpretations, so does the nature of digital surrogacy. It has been suggested here that the inherent value of surrogates is socially constructed and is therefore subject to being altered. In an increasingly digital world, archivists and cultural heritage institutions will likely see an adjustment in notions of value and definitions of preservation as digitized and born-digital collections grow. The acceptance of digital surrogacy as a tool and method of archival preservation is based entirely on shifting the perceptions and expectations of users and collection managers. This change in attitude must accompany the treatment of digital objects as a valuable archival source, and user behavior/experience is the key defining principle for this shift.

Due to the visual nature and multiplicity of material forms within photographic collections, the concerns surrounding digitization are not misplaced. However, the prevailing argument that the material qualities of photographs cannot be faithfully rendered in a digital environment does not account for the selection process, advancements in contemporary imaging technologies, or the archivist's labor in creating descriptive metadata. To claim that digitization does not equate to preservation because it preserves only content and not form or context is misguided, as it is not the materiality that is lost, but rather the substance that is not able to be rendered digitally.

In the same way that aging and reformatting in an archive disrupt preservation attempts in a practical sense, not every element of materiality will be preserved in the digital surrogate. However, the embodiment of the physical object is carried into the

25. Bruno Latour and Adam Lowe, "The Migration of the Aura—or How to Explore the Original through Its Facsimiles," in Switching Codes: Thinking Through Digital Technology in the Humanities and the Arts, eds. Thomas Bartscherer and Roderick Coover (Chicago: University of Chicago Press, 20II), 278.

26. Burns, "Digital Facsimiles and the Modern Viewer," I59. 
digital file through selective and reliable digital capture, robust descriptive and technical metadata, and wide dissemination. Through these processes, Benjamin's "aura" is not only retained in photographic collections, but it is preserved and amplified to an extent that the singularity and originality of the physical archival photograph depends almost entirely upon the existence of its digital copies. 